\title{
In Vivo Amphetamine Action is Contingent on aCaMKII
}

\author{
Thomas Steinkellner', Liudmilla Mus ${ }^{2,3}$, Birgit Eisenrauch', Andreea Constantinescu', Damiana Leo ${ }^{2}$, \\ Lisa Konrad', Mattias Rickhag ${ }^{4}$, Gunnar S $₫$ rensen ${ }^{4}$, Evgenia V Efimova ${ }^{5}$, Eryan Kong ${ }^{6}$, Matthäus Willeit ${ }^{7}$, \\ Tatyana D Sotnikova ${ }^{2}$, Oliver Kudlacek', Ulrik Gether ${ }^{4}$, Michael Freissmuth', Daniela D Pollak', \\ Raul R Gainetdinov ${ }^{2,5,8}$ and Harald H Sitte ${ }^{*, 1}$
}

I'Institute of Pharmacology, Center for Physiology and Pharmacology, Medical University Vienna, Waehringer Strasse, Vienna, Austria; ${ }^{2}$ Department of Neuroscience and Brain Technologies, Istituto Italiano di Tecnologia (IIT), Via Morego, Genova, Italy; ${ }^{3}$ Department of Psychopharmacology, Institute of Pharmacology, Pavlov Medical University, St Petersburg, Russia; ${ }^{4}$ Molecular Neuropharmacology and Genetics Laboratory, Department of Neuroscience and Pharmacology, Faculty of Health and Medical Sciences, The Panum Institute, University of Copenhagen, Copenhagen, Denmark; ${ }^{5}$ Skolkovo Institute of Science and Technology (Skoltech), Skolkovo, Moscow, Russia; ${ }^{6}$ Department of Neurophysiology and Neuropharmacology, Center for Physiology and Pharmacology, Medical University Vienna, Waehringer Strasse, Vienna, Austria; ' Department of Psychiatry and Psychotherapy, Medical University of Vienna, Waehringer Guertel, Vienna, Austria; ${ }^{8}$ Faculty of Biology and Soil Science, St Petersburg State University, St Petersburg, Russia

\begin{abstract}
Addiction to psychostimulants (ie, amphetamines and cocaine) imposes a major socioeconomic burden. Prevention and treatment represent unmet medical needs, which may be addressed, if the mechanisms underlying psychostimulant action are understood. Cocaine acts as a blocker at the transporters for dopamine (DAT), serotonin (SERT), and norepinephrine (NET), but amphetamines are substrates that do not only block the uptake of monoamines but also induce substrate efflux by promoting reverse transport. Reverse transport has been a focus of research for decades but its mechanistic basis still remains enigmatic. Recently, transporter-interacting proteins were found to regulate amphetamine-triggered reverse transport: calmodulin kinase $\| \alpha(\alpha \mathrm{CaMKII})$ is a prominent example, because it binds the carboxyl terminus of DAT, phosphorylates its amino terminus, and supports amphetamine-induced substrate efflux in vitro. Here, we investigated whether, in vivo, the action of amphetamine was contingent on the presence of $\alpha$ CaMKII by recording the behavioral and neurochemical effects of amphetamine. Measurement of dopamine efflux in the dorsal striatum by microdialysis revealed that amphetamine induced less dopamine efflux in mice lacking $\alpha$ CaMKII. Consistent with this observation, the acute locomotor responses to amphetamine were also significantly blunted in $\alpha$ CaMKII-deficient mice. In addition, while the rewarding properties of amphetamine were preserved in $\alpha$ CaMKII-deficient mice, their behavioral sensitization to amphetamine was markedly reduced. Our findings demonstrate that amphetamine requires the presence of $\alpha$ CaMKII to elicit a full-fledged effect on DAT in vivo: $\alpha$ CaMKII does not only support acute amphetamine-induced dopamine efflux but is also important in shaping the chronic response to amphetamine. Neuropsychopharmacology (2014) 39, 268I-2693; doi:I0.1038/npp.20I4.124; published online 25 June 20I4
\end{abstract}

\section{INTRODUCTION}

Amphetamines constitute a class of psychostimulants that share a phenylethylamine core structure. They are used illicitly for recreational purposes, but also used clinically for the treatment of attention-deficit hyperactivity disorder (ADHD) and narcolepsy (Kristensen et al, 2011; Steinkellner et al, 2011). The stimulant and addictive properties of amphetamines are thought to arise primarily from their interaction with the cocaine-sensitive dopamine transporter (DAT) (Sulzer, 2011). DAT is a member of the solute carrier 6 gene family of $\mathrm{Na}^{+} / \mathrm{Cl}^{-}$-dependent neurotransmitter transporters; these transporters terminate neurotransmission

*Correspondence: Professor HH Sitte, Institute of Pharmacology, Center for Physiology and Pharmacology, Medical University Vienna, Waehringer Strasse 13A, Vienna 1090, Austria, Tel: +43 | 40 I60 31323, Fax: +43 | 40160 931300, E-mail: harald.sitte@meduniwien.ac.at Received 9 January 20 I4; revised I May 20।4; accepted 5 May 20 4; accepted article preview online 29 May 2014 by clearing the synapse of their cognate substrate(s) (Kristensen et al, 2011). Amphetamines are substrates of DAT and compete for reuptake with dopamine (Sitte et al, 1998). In addition, amphetamines can induce transport reversal leading to transporter-mediated efflux of dopamine (Sulzer, 2011; Sitte and Freissmuth, 2010). Both, competition for uptake and reverse transport lead to a pronounced increase in the extracellular concentrations of dopamine. The resulting increased dopaminergic input in the striatum has been associated with the rewarding properties of amphetamines (Schultz, 2002). Accordingly, repeated amphetamineinduced enhancement of synaptic dopamine can promote the development of drug addiction via the induction of longterm changes leading to synaptic plasticity (Nestler, 2005; Sulzer, 2011). In addition, the adaptive changes have been implicated in the emergence of stimulant-induced psychosis and schizophrenia (Snyder, 1974; Yui et al, 1999).

The molecular mechanism of amphetamine-induced DAT-mediated reverse transport is still a matter of debate 
(Sulzer, 2011; Sitte and Freissmuth, 2010). Reverse transport is thought to involve the uptake of amphetamines via the transporter and their passive diffusion through the membrane which is due to their lipophilic nature (Sitte et al, 1998; Sandtner et al, 2013). Besides, the weak-base hypothesis states that amphetamines are trapped within synaptic vesicles in the presynaptic specialization and deplete the vesicular stores of dopamine by dissipating the proton gradient that provides the driving force for the vesicular monoamine transporters (VMATs). Thereby, amphetamines elevate the cytosolic dopamine concentration and render dopamine available for reverse transport by DAT (Sulzer, 2011). Additionally, amphetamine is a substrate for VMATs and thereby competitively inhibits vesicular dopamine uptake. The resulting elevation of dopamine in the cytosol provides another explanation for how dopamine can efflux via DAT (Sulzer, 2011).

Undoubtedly, ion gradients are the most crucial factor in determining whether transporter reversal can occur, because the substrate-binding sites are only accessible in the presence of high $\mathrm{Na}^{+}$concentrations (Sitte and Freissmuth, 2010). A crucial factor for amphetamine-induced reverse transport of DAT is its contingency on the intracellular sodium concentration (Khoshbouei et al, 2003). However, the last years also revealed an intricate contribution of both, the membrane environment and interacting proteins (Fog et al, 2006; Steinkellner et al, 2012; Pizzo et al, 2013, 2014; Buchmayer et al, 2013) in the modulation of amphetamine-triggered reverse transport. Previous observations also indicated that dopamine efflux was regulated by cytosolic $\mathrm{Ca}^{2+}$ (Gnegy et al, 2004). Because of its abundance in neurons, $\mathrm{Ca}^{2+} /$ calmodulin-dependent protein kinase II $\alpha$ ( $\alpha$ CaMKII) was the candidate target of $\mathrm{Ca}^{2+}$. This was subsequently verified: $\alpha$ CaMKII was shown to modulate reverse transport of dopamine by binding to the carboxyl terminus of DAT and to phosphorylate serines at its amino terminus (Fog et al, 2006). In vitro, inhibition of $\alpha \mathrm{CaMKII}$ and its genetic ablation attenuated the amphetamine-induced substrate efflux via DAT (Fog et al, 2006; Steinkellner et al, 2012; Rickhag et al, 2013). These results supported the hypothesis that $\alpha$ CaMKII regulated the action of amphetamine on DAT.

The amphetamine-induced behavioral effects result from the complex interplay of at least three target areas, which are innervated by dopaminergic projection neurons. These include the prefrontal cortex, where dopamine impinges on executive function, the nucleus accumbens, in which dopamine encodes rewarding cues and incentive salience, and the corpus striatum, where dopamine controls locomotion. Dopaminergic projections in the brain express DAT at different levels. It is therefore not clear whether components of the amphetamine-induced behavioral response differ in their dependence on $\alpha$ CaMKII.

We addressed this question by exploring the action of amphetamine in vivo in $\alpha$ CaMKII-deficient mice. We found that the absence of $\alpha$ CaMKII blunted both the amphetamine-induced increase in locomotion and the sensitization after repeated administration of amphetamine. Surprisingly, the rewarding action of amphetamine was preserved in $\alpha$ CaMKII-deficient mice. These findings demonstrate that, in vivo, some-but not all-actions of amphetamine are contingent on functional $\alpha$ CaMKII.

\section{MATERIALS AND METHODS}

\section{Reagents}

D-amphetamine, cocaine, GBR12909, cis-(Z)-flupenthixol, haloperidol, ketanserin, 3-hydroxybenzylhydrazine (ND1015), reserpine, and the anti- $\alpha$-Tubulin antibody were purchased from Sigma Aldrich; $\left[{ }^{3} \mathrm{H}\right]$ dopamine $(40 \mathrm{Ci} / \mathrm{mmol})$, $\left[{ }^{3} \mathrm{H}\right] \mathrm{SCH} 23390(70 \mathrm{Ci} / \mathrm{mmol})$, and $\left[{ }^{3} \mathrm{H}\right]$ raclopride $(60 \mathrm{Ci} /$ mmol) were obtained from PerkinElmer Life Sciences. Anti-tyrosine hydroxylase and anti-VMAT2 antibodies were purchased from Merck Millipore. Anti-PSD-95 and antiDARPP32 antibodies were from BD Transduction Laboratories. Anti- $\beta$ CaMKII antibody was from Life Technologies. Anti-PKC antibody was obtained from Signalway Antibody LLC. Anti-phospho Akt Thr-308, anti-phospho DARPP32 Thr-34, anti-phospho ERK1/2 (p44/42) Thr-202/Tyr-204, anti-total Akt, and anti-total ERK1/2 antibodies were purchased from Cell Signaling Technology.

\section{Animals}

The generation of $\alpha$ CaMKII-KO mice has been described elsewhere (Elgersma et al, 2002). All mice were bred on a C57Bl/6J background and were housed under standard laboratory conditions (12-h light/12-h dark cycle). Food and water were provided ad libitum. Male mice were tested at 12-20 weeks of age. All experiments were conducted in accordance with protocols approved by the Animal Welfare Committee of the Medical University of Vienna and the Austrian Federal Ministry of Science and Research (license $\mathrm{BMWF} \cdot 66.009 / 0250-\mathrm{II} / 3 \mathrm{~b} / 2013)$.

\section{Synaptosomal and Vesicular $\left[{ }^{3} \mathrm{H}\right]$ Dopamine Uptake and Radioligand Binding}

Uptake of $\left[{ }^{3} \mathrm{H}\right]$ dopamine via DAT was measured in striatal synaptosomes as described (Steinkellner et al, 2012). Vesicular uptake was performed in striatal synaptic vesicles. Briefly, lysate pellet 2 (LP2) was isolated as described by Hell and Jahn (1994) and resuspended in uptake buffer (150 mM N-methyl-D-glucamine (NMDG), $10 \mathrm{mM}$ HEPES, $2 \mathrm{mM}$ ATP- $\mathrm{Mg}^{2+}, 2 \mathrm{mM} \mathrm{KCl}$, and $10 \mathrm{mM} \mathrm{K} \mathrm{K}^{+}$-gluconate, $\mathrm{pH}=7.4$ ). To measure transport, approximately $20-30 \mu \mathrm{g}$ of vesicles were preincubated in uptake buffer for $10 \mathrm{~min}$ at $30{ }^{\circ} \mathrm{C}$ before the addition of $40 \mathrm{nM}\left[{ }^{3} \mathrm{H}\right]$ dopamine and incubation for another $10 \mathrm{~min}$ at $30^{\circ} \mathrm{C}$. Non-specific uptake was done in the presence of $10 \mu \mathrm{M}$ reserpine. Uptake was terminated by the addition of ice-cold uptake buffer $(2 \mathrm{mM}$ ATP- $\mathrm{Mg}^{2+}$ was substituted by $2 \mathrm{mM} \mathrm{MgSO}$ ) and filtration using $\mathrm{GF} / \mathrm{B}$ filters presoaked in $2 \%$ polyethylenimine.

Binding of $\left[{ }^{3} \mathrm{H}\right] \mathrm{SCH} 23390$ and $\left[{ }^{3} \mathrm{H}\right]$ raclopride was performed as described (Ghisi et al, 2009). Briefly, striatal synaptosomes (Steinkellner et al 2012) were resuspended in binding buffer ( $50 \mathrm{mM}$ Tris $\mathrm{HCl}, 120 \mathrm{mM} \mathrm{NaCl}, 5 \mathrm{mM} \mathrm{KCl}$, $\left.2 \mathrm{mM} \mathrm{CaCl}_{2}, 1 \mathrm{mM} \mathrm{MgCl}, \mathrm{pH}=7.4\right)$. Ketanserin $(100 \mathrm{nM})$ was added to the incubation to prevent binding of $\left[{ }^{3} \mathrm{H}\right] \mathrm{SCH} 23390$ to $5 \mathrm{HT}_{2 \mathrm{~A}}$ receptors. Increasing concentrations of $\left[{ }^{3} \mathrm{H}\right] \mathrm{SCH} 23390$ or $\left[{ }^{3} \mathrm{H}\right]$ raclopride were added; the reaction was incubated for $1 \mathrm{~h}$ at $25^{\circ} \mathrm{C}$. Non-specific binding was determined in the presence of $10 \mu \mathrm{M}$ cis-(Z)flupenthixol and $50 \mu \mathrm{M}$ haloperidol for $\left[{ }^{3} \mathrm{H}\right] \mathrm{SCH} 23390$ and $\left[{ }^{3} \mathrm{H}\right]$ raclopride binding, respectively. Binding was stopped 
by adding ice-cold binding buffer and filtered onto GF/B filters presoaked in $2 \%$ polyethylenimine using an automated cell harvester filtration device (Skatron Instruments AS). The radioactivity bound to the filters was measured by liquid scintillation counting.

\section{Immunoblots}

Mice were killed by cervical dislocation, decapitated, and heads were immediately immersed in liquid nitrogen for $6 \mathrm{~s}$. Striata were dissected and snap-frozen in liquid nitrogen. Tissue was homogenized in RIPA buffer containing $(50 \mathrm{mM}$ Tris. $\mathrm{HCl}, 150 \mathrm{mM} \mathrm{NaCl}, 1 \mathrm{mM}$ EDTA, $1 \%$ Triton X-100, $0.1 \%$ SDS, and $1 \%$ deoxycholate supplemented with protease and phosphatase inhibitors) and incubated at $4{ }^{\circ} \mathrm{C}$ for $60 \mathrm{~min}$ followed by centrifugation at $12600 \mathrm{~g}$ for $30 \mathrm{~min}$. For phospho-protein analysis, tissue was boiled for $10 \mathrm{~min}$ in $1 \%$ SDS supplemented with protease and phosphatase inhibitors (Roche). Proteins were separated on a 10\% SDS-PAGE and electrotransferred onto nitrocellulose before incubation with primary antibodies overnight. IRDye 680 - or $800-R D$-labeled secondary antibodies were obtained from LI-COR and visualized using the LI-COR Odyssey CLx infrared imaging system. Densitometric quantification of bands was performed using NIH ImageJ software.

\section{Behavioral Pharmacology}

Horizontal locomotion (total distance traveled) was measured in 'open-field' (OF) square boxes $(36 \times 36 \times 45 \mathrm{~cm})$ using a video camera mounted above the box and analyzed using the Anymaze software from Stoelting (V.4.7). Distances traveled were recorded for $60 \mathrm{~min}$. Acute drug effects were assessed by administering an intraperitoneal (i.p.) injection of saline to the mice on day zero (d0); their locomotion was measured for $60 \mathrm{~min}$. On the next day (d1), mice were administered D-amphetamine ( 2 or $5 \mathrm{mg} / \mathrm{kg}$ ) by i.p. injection. Distances traveled were again recorded for $60 \mathrm{~min}$. Acute drug effects were normalized to the distances traveled upon injection of saline and expressed as fold increase in locomotion.

D-amphetamine-induced locomotor sensitization. Baseline locomotor activity of mice was assessed on day zero (d0) after injection of saline (i.p.). Mice were then sensitized to D-amphetamine $(2 \mathrm{mg} / \mathrm{kg}$ ) by daily (i.p.) injections for 6 consecutive days (d1-d6). After each injection, locomotor activity was recorded in the OF boxes for $60 \mathrm{~min}$. After 6 days of drug sensitization, amphetamine was withheld for 14 days. Mice were challenged by injection of D-amphetamine $(2 \mathrm{mg} / \mathrm{kg}$, i.p.) on day $20(\mathrm{~d} 20)$ after which they were again monitored in the OF boxes.

Conditioned place preference. Conditioned place preference (CPP) was conducted in commercially available CPP chambers (MED Associates, Georgia, VT, USA) using the protocol described in Ramsey et al (2008). The apparatus used consisted of two chambers with distinguishable floor (grid floor $v s$ rod floor). Experiments consisted of preconditioning, conditioning, and test phases. During preconditioning (d0) mice had free access to both chambers for
30 min; the time spent in both chambers was recorded. On the next day (d1), mice were injected i.p. with D-amphetamine $(2 \mathrm{mg} / \mathrm{kg}$ or $5 \mathrm{mg} / \mathrm{kg})$ or cocaine $(20 \mathrm{mg} / \mathrm{kg})$ and put into the less-preferred chamber for $30 \mathrm{~min}$. On the following day (d2), saline was injected and mice were put into the other chamber for $30 \mathrm{~min}$. This procedure was repeated two more times with alternating drug $(\mathrm{d} 3, \mathrm{~d} 5)$ and saline (d4, d6) injections. On the last day (d7), mice were put into the apparatus and allowed to access both chambers to test for conditioned place preference. The time spent in each chamber was recorded for $30 \mathrm{~min}$.

\section{In Vivo Microdialysis}

Mice were anaesthetized using ketamine $(100 \mathrm{mg} / \mathrm{kg}) /$ xylazine $(10 \mathrm{mg} / \mathrm{kg})$ and placed into a stereotactic frame (Stoelting). Concentric microdialysis probes $(2-\mathrm{mm}$ membrane length; cutoff $6000 \mathrm{Da}$; CMA-11, CMA/Microdialysis, Solna, Sweden) were inserted into the right dorsal striatum using the following coordinates (in $\mathrm{mm}$ ) according to Franklin and Paxinos (2008): anterior-posterior: 0.0; lateral: - 2.5; dorso-ventral: 4.4. A screw was inserted into the left hemisphere to stabilize subsequent fixation with dental cement. Twenty-four hours after surgery, freely moving animals were connected to a syringe pump and perfused with artificial cerebrospinal fluid (aCSF: $147 \mathrm{mM}$

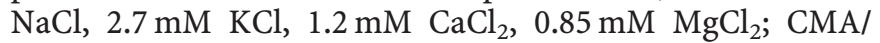
Microdialysis, Solna, Sweden). After a washout for $1 \mathrm{~h}$, four 90-min fractions were collected in a low-perfusion mode $(0.1 \mu \mathrm{l} / \mathrm{min})$ in tubes containing $2 \mu \mathrm{l}$ of $0.5 \mathrm{M}$ perchloric acid to estimate the extracellular dopamine concentrations in the striatum (Gainetdinov et al, 2003).

Twenty-four hours after the low-perfusion mode, mice were again connected to the pump and perfusion was performed using 'conventional microdialysis' $(1 \mu \mathrm{l} / \mathrm{min})$ to measure the effect of D-amphetamine on DAT-mediated dopamine efflux in freely moving animals (Gainetdinov et al, 2003). After a 30-min washout, $6 \times 20$-min baseline fractions were collected. After that, mice were injected with saline and $6 \times 20$-min fractions were collected. Finally, mice were injected with $5 \mathrm{mg} / \mathrm{kg} \mathrm{D}$-amphetamine and $6 \times 20$-min fractions were collected. All these samples were collected in tubes containing $2 \mu \mathrm{l}$ of $1 \mathrm{M}$ perchloric acid

All dialysis samples were analyzed using reversed-phase high-performance liquid chromatography with electrochemical detection (HPLC-EC) to measure the levels of dopamine and its metabolites.

\section{Neurochemical Measurement of Monoamine Tissue Levels}

Striata were dissected and frozen in liquid nitrogen. For L-DOPA measurements, mice were injected with $100 \mathrm{mg} / \mathrm{kg}$ (i.p.) of 3-hydroxybenzylhydrazine (ND1015) $1 \mathrm{~h}$ before killing. Tissue was homogenized in 40 volumes of $0.1 \mathrm{M}$ $\mathrm{HClO}_{4}$, the homogenate was centrifuged at $10000 \mathrm{~g}$ for $10 \mathrm{~min}$ and supernatants were filtered through $0.22 \mu \mathrm{m}$ filters (Millipore Ultrafree-MC centrifugal filter units, $0.22 \mu \mathrm{m})$.

Analytical procedure. Measurements of dopamine and metabolites in collected microdialysis and tissue samples 
were performed by HPLC with electrochemical detection (ALEXYS LC-EC system, Antec Leyden BV, the Netherlands) equipped with a reverse-phase column $(3 \mu \mathrm{m}$ particles, ALB-215 C18, $1 \times 150 \mathrm{~mm}$, Antec) at a flow rate of $200 \mu \mathrm{l} / \mathrm{min}$ and electrochemically detected by a $0.7-\mathrm{mm}$ glass carbon electrode (Antec; VT-03). The mobile phase contained $50 \mathrm{mM} \mathrm{H}_{3} \mathrm{PO}_{4}, 50 \mathrm{mM}$ citric acid, $8 \mathrm{mM} \mathrm{KCl}$, $0.1 \mathrm{mM}$ EDTA, $400 \mathrm{mg} / \mathrm{l}$ octanesulfonic acid sodium salt, and $10 \%$ (vol/vol) methanol, $\mathrm{pH}$ 3.9. The sensitivity of the method permitted detection of $\sim 3 \mathrm{fmol}$ dopamine. All samples $(11 \mu \mathrm{l})$ were injected into HPLC without any additional purification.

\section{Fast-Scan Cyclic Voltammetry (FSCV)}

Briefly, mice were anaesthetized with halothane and decapitated. The brain was sectioned in cold carboxygenated aCSF on a VT1000S vibrating microtome (Leica Microsystems, Nussloch, Germany) at a thickness of $300 \mu \mathrm{m}$. Coronal slices containing the dorsal striatum were allowed to recover for at least $1 \mathrm{~h}$ at room temperature in carboxygenated aCSF. For recordings, slices were superfused with $32{ }^{\circ} \mathrm{C}$ carboxygenated aCSF at a flow rate of $1 \mathrm{ml} / \mathrm{min}$. Experimental recordings started $20 \mathrm{~min}$ after transfer to the slice chamber. Carbon fiber electrodes ( $5 \mu \mathrm{m}$; Goodfellow, Huntingdon, England) were made as previously described (Kuhr and Wightman, 1986). The electrodes were inserted $\sim 100 \mu \mathrm{m}$ into the dorsal striatal brain slice. The potential of the working electrode was held at $-0.4 \mathrm{~V} v s \mathrm{Ag} / \mathrm{AgCl}$ between scan and was ramped to $+1.3 \mathrm{~V}$ at $300 \mathrm{~V} / \mathrm{s}$ and back at $-0.4 \mathrm{~V}$ every $100 \mathrm{~ms}$ via an A-M system isolated pulse stimulator (Sequim, WA, USA). The triangular waveform was computer-controlled using HEKA EVA8 potensiostat (HEKA Elektronik Dr Schulze $\mathrm{GmbH}$, Germany) and a ESA bioscience FSCV interface analog to digital converter) via $\mathrm{TH}-1$ software (ESA biosciences, MA, USA). Axonal dopamine release in the dorsolateral striatum was evoked using a twisted bipolarstimulating electrode (Plastics One, Roanoke, VA, USA). Stimulations were delivered every $2 \mathrm{~min}$ by a single electrical pulse ( $1 \mathrm{~ms}, 400 \mu \mathrm{s})$. Background-subtracted cyclic voltammograms were obtained by subtracting the current obtained before the stimulation from all recordings. The peak oxidation current for dopamine in each voltammogram was converted into a measure of the dopamine concentration by postcalibration of the electrode using $1 \mu \mathrm{M}$ dopamine (Sigma Aldrich, Milan, Italy). Data were normalized to the first five recordings $(10 \mathrm{~min})$ of their respective control period and graphically plotted against time (means \pm SEM). We reported in Figure $3 \mathrm{~b}$ the dopamine concentration measured and we used normalized current in all the other graphs.

\section{Statistics}

The statistical significance of differences was evaluated using one-way ANOVA followed by Tukey's post hoc test or Student's $t$-test where appropriate. Data are shown as mean \pm SEM.

\section{RESULTS \\ $\alpha$ CaMKII-KO Mice Still Develop Conditioned Place Preference for Amphetamine}

In its multimeric arrangement, individual $\alpha$ CaMKII moieties phosphorylate adjacent monomers and thus store information that encodes the magnitude of a preceding calcium signal. Accordingly, $\alpha$ CaMKII supports long-term potentiation and thus the initial steps required in the formation of some types of memory (Silva et al, 1992). The intrahippocampal injection of the CaMKII-inhibitor KN-93 impairs conditioned place preference (CPP) for D-amphetamine in rats (Tan, 2002). We therefore anticipated that CPP would be abrogated in $\alpha$ CaMKII-deficient mice. However, this was not the case. Regardless of whether D-amphetamine was administered at a dose of $2 \mathrm{mg} / \mathrm{kg}$ or $5 \mathrm{mg} / \mathrm{kg}$, $\alpha$ CaMKII-deficient mice did not significantly differ from wild-type mice in their ability to recall the spatial memory associated with drug administration (Figure $1 \mathrm{a}$ and $\mathrm{b}$ ). As a control, we determined CPP upon administration of the DAT-inhibitor cocaine $(20 \mathrm{mg} / \mathrm{kg})$ : the rewarding properties of cocaine were similar in magnitude in wild type and $\alpha$ CaMKII-KO mice (Figure 1c). Taken together, these data show that $\alpha$ CaMKII is not required for the rewarding effect of amphetamine and cocaine as measured by CPP.

\section{$\alpha$ CaMKII-KO Mice Display Increased Locomotor Activity and have Elevated Extracellular Dopamine Concentrations}

A null mutation of unc-43, the Caenorhabditis elegans homolog of $\alpha$ CaMKII, causes hyperactivity in the nematode (Reiner et al, 1999). Hence, we recorded the baseline locomotor activities of $\alpha \mathrm{CaMKII-KO}$ and wild-type mice to assess whether motor activity was affected by the loss of $\alpha$ CaMKII. Within the $1-\mathrm{h}$ observation period in the OF, $\alpha$ CaMKII-KO mice covered a roughly threefold longer distance than wild-type mice (Figure 2a). Mice deficient in DAT (DAT-KO) have increased basal extracellular dopamine levels and are hyperactive (Giros et al, 1996; Jones et al, 1998). Accordingly, we also monitored locomotion of DAT-KO mice in the OF to gauge the magnitude of the effect seen in $\alpha$ CaMKII-KO mice. This control experiment indicated that the hyperactivity seen in $\alpha$ CaMKII-KO mice is approximately threefold less pronounced than that of DAT-KO mice (DAT-KO: $503 \pm 71 \mathrm{~m}, n=5 ; p<0.0001$ ). The hyperactivity of DAT-KO mice is accounted for by elevated extracellular dopamine levels (Giros et al, 1996). Hence, we measured striatal extracellular dopamine levels in $\alpha$ CaMKIIKO mice. Baseline extracellular dopamine concentrations are at low nanomolar range, but can be measured reliably by microdialysis employing a quantitative low-perfusion rate microdialysis $(0.1 \mu \mathrm{l} / \mathrm{min})$. Our results showed that basal dopamine levels were approximately twofold higher in the dorsal striatum of $\alpha$ CaMKII-KO mice compared with wildtype littermates (Figure $2 \mathrm{~b}$ ). In addition, the total tissue content of striatal dopamine was significantly increased in $\alpha$ CaMKII-KO mice (Figure 2c) without concomitant changes in the dopamine metabolites 3,4-dihydroxyphenylacetic acid and homovanillic acid (data not shown). At the same time, the dopamine turnover (DOPAC/dopamine ratio) was not altered (data not shown). 

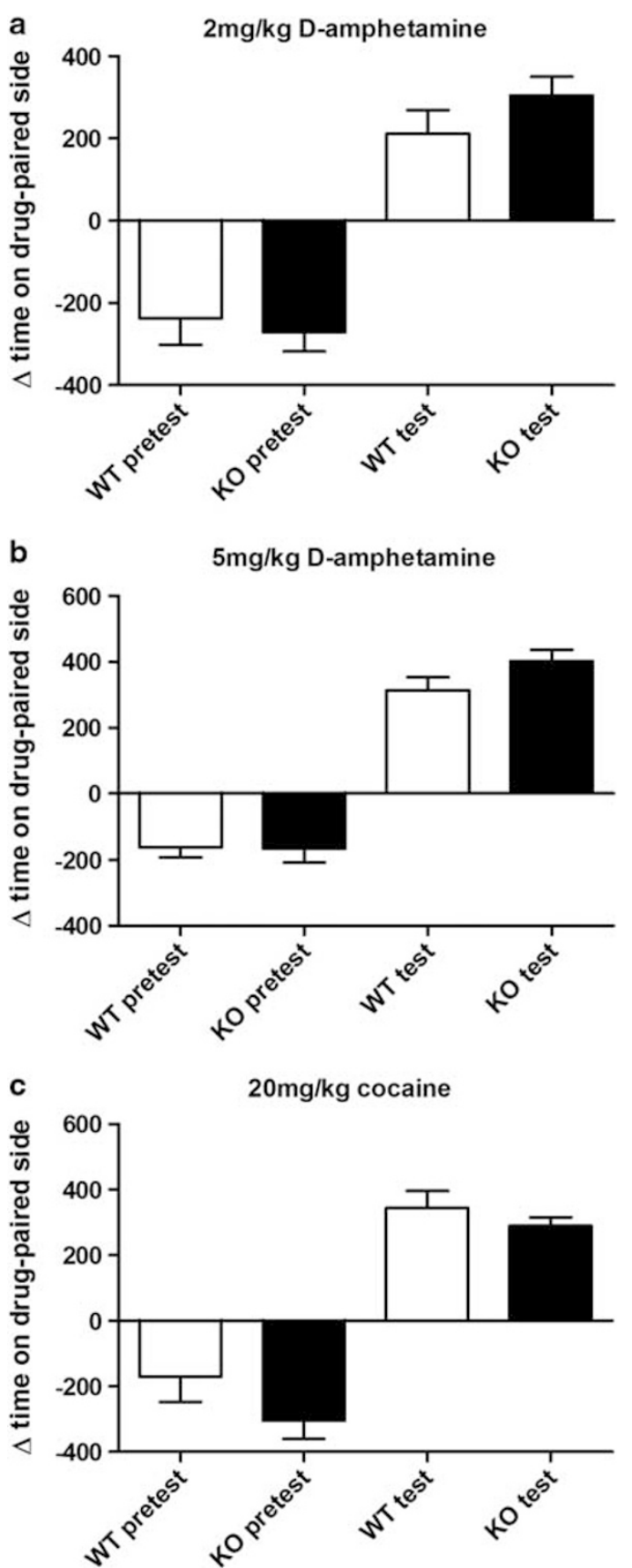

Figure I Conditioned place preference for $2 \mathrm{mg} / \mathrm{kg}$ (a) and $5 \mathrm{mg} / \mathrm{kg}$ (b) D-amphetamine and $20 \mathrm{mg} / \mathrm{kg}$ cocaine (c); (stimulants were administered in the less-preferred chamber): data are expressed as the time spent in the drug-associated compartment before (pretest) and after (test) D-amphetamine or cocaine treatment. D-amphetamine $(2 \mathrm{mg} / \mathrm{kg}$ and $5 \mathrm{mg} / \mathrm{kg})$ and cocaine induced significant place preference in both, wild type (WT) and knockout (KO) mice (paired two-tailed Student's t-test, $p<0.0 \mathrm{I}$ ). Repeated measures two-way analysis of variance (ANOVA) revealed no significant treatment $\times$ genotype effects $(p<0.05)$. (a) $\mathrm{WT} n=7, \mathrm{KO}$ $n=13$, (b) $\mathrm{WT} n=10, \mathrm{KO} n=10$, (c) WT $n=7, \mathrm{KO} n=5$.

The difference in dopamine levels may arise from a change in the dopamine synthesis rate in $\alpha$ CaMKIIKO mice. Accordingly, we blocked the second step in dopamine biosynthesis by pre-treating mice with 3-hydroxybenzylhydrazine (ND1015, $100 \mathrm{mg} / \mathrm{kg}$ i.p.), an inhibitor of L-aromatic amino acid decarboxylase, which readily permeates the blood-brain barrier. After $1 \mathrm{~h}$, mice were killed, striata were harvested, and the levels of the dopamine precursor L-DOPA were determined as an index of the dopamine synthesis rate. L-DOPA levels were not significantly different between genotypes ( $\alpha$ CaMKII-KO: $1.57 \pm 0.14 \mathrm{ng} / \mathrm{mg}$, WT: $1.24 \pm 0.14 \mathrm{ng} / \mathrm{mg} ; n=7 ; p=0.1264)$. In addition, we quantified the expression level of tyrosine hydroxylase by immunoblotting and found that the striata of wild type and $\alpha$ CaMKII-KO mice contained comparable amounts of the enzyme (Figure 2d).

In conclusion, our results indicate that the absence of $\alpha$ CaMKII was associated with increased extracellular and total levels of dopamine and pronounced hyperactivity.

\section{Vesicular Dopamine Release is Increased in $\alpha$ CaMKII-KO Mice}

An increase in extracellular dopamine can be accounted for by at least two mechanisms, which are not necessarily mutually exclusive: (i) a decrease in dopamine reuptake and/or (ii) increased vesicular release of dopamine. We previously showed that the uptake rate of the DAT substrate $\left[{ }^{3} \mathrm{H}\right]$ 1-methyl-4-phenylpyridinium $\left(\left[{ }^{3} \mathrm{H}\right] \mathrm{MPP}^{+}\right)$was unchanged in striatal synaptosomes of $\alpha$ CaMKII-KO mice (Steinkellner et al 2012). $\left[{ }^{3} \mathrm{H}\right] \mathrm{MPP}^{+}$was used because it is more stable than dopamine and does not diffuse through the membrane. We ruled out subtle changes in handling different substrates by also carrying out uptake experiments in striatal synaptosomes of $\alpha$ CaMKII-KO and wild-type mice using $\left[{ }^{3} \mathrm{H}\right]$ dopamine; the observations confirmed that uptake of the endogenous substrate was similar with respect to both, the maximal velocity of uptake $\left(V_{\max }\right)$ and the apparent affinity for dopamine $\left(K_{\mathrm{m}}\right)$ (Figure $3 \mathrm{a}$ ). In line with unchanged dopamine uptake kinetics, we previously showed that DAT surface expression was not altered in the striatum of $\alpha$ CaMKII-KO mice (Steinkellner et al, 2012). Hence, reduced dopamine uptake is unlikely to account for higher basal levels of dopamine in $\alpha$ CaMKII-KO mice.

We also explored the alternative explanation, namely that vesicular release of dopamine was altered: striatal slices were prepared from $\alpha$ CaMKII-KO and wild-type mice subjected to a single electrical pulse of $400 \mu \mathrm{A}$ and $1 \mathrm{~ms}$ duration. This manipulation induces dopamine release from vesicles of the readily releasable pool at the active zone of dopaminergic terminals. Dopamine released in response to the electrical pulse was measured by fast-scan cyclic voltammetry. The signals recorded in slices from $\alpha \mathrm{CaM}-$ KII-KO mice were consistently larger than that observed in those of wild-type mice, indicating that vesicular dopamine release was enhanced in $\alpha$ CaMKII-KO (Figure $3 b$ and c).

The increase in vesicular dopamine release does not seem to be contingent on increased VMAT2 levels or elevated vesicular dopamine uptake: we measured both, total VMAT2 protein levels in the striatum and reserpinesensitive dopamine uptake in purified striatal synaptic vesicles. Our results indicated that neither the VMAT2 total protein amount nor the vesicular uptake rate of $\left[{ }^{3} \mathrm{H}\right] \mathrm{dopa}-$ mine was significantly altered between wild type and $\alpha \mathrm{CaMKII-KO}$ animals (Figure $3 \mathrm{~d}$ and e). 
Dopamine Receptors, Dopamine Signaling, and PSD-95 Protein Levels in $\alpha$ CaMKII-KO Mice

The findings summarized in Figures 2 and 3 per se suffice to account for the hyperactive phenotype of $\alpha$ CaMKII-KO mice, because (i) the increased dopamine tissue levels translate into (ii) enhanced vesicular dopamine release and thus drive locomotion. Elevated extracellular dopamine levels affect dopamine receptor-mediated signaling in DATKO mice. Therefore, we also examined the postsynaptic targets of dopamine in the striatum of $\alpha$ CaMKII-deficient mice, ie, dopamine $D_{1}$ and $D_{2}$ receptors as well as three prototypic dopamine-related signaling pathways (DARPP32,
Akt, and ERK1/2; all of which are altered in DAT-KO mice). Furthermore, we examined the scaffolding protein PSD95 (postsynaptic density protein of $95 \mathrm{kD}$ ) which plays a key role in organizing signaling molecules on the postsynaptic membrane. Dopamine $D_{1}$ and $D_{2}$ receptor expression levels were quantified by binding of $\left[{ }^{3} \mathrm{H}\right] \mathrm{SCH} 23390$ and $\left[{ }^{3} \mathrm{H}\right] \mathrm{ra}-$ clopride to striatal membranes, respectively (Figure $3 \mathrm{f}$ and $\mathrm{g}$ ). In contrast to what could have been expected with regard to the hyperdopaminergic DAT-KO mice, we did not observe any significant differences in the number of $\mathrm{D}_{1}$ and $\mathrm{D}_{2}$ receptors in striatal membranes of $\alpha$ CaMKII-KO and wild-type mice (Figure $3 \mathrm{~d}$ and e). In line with the
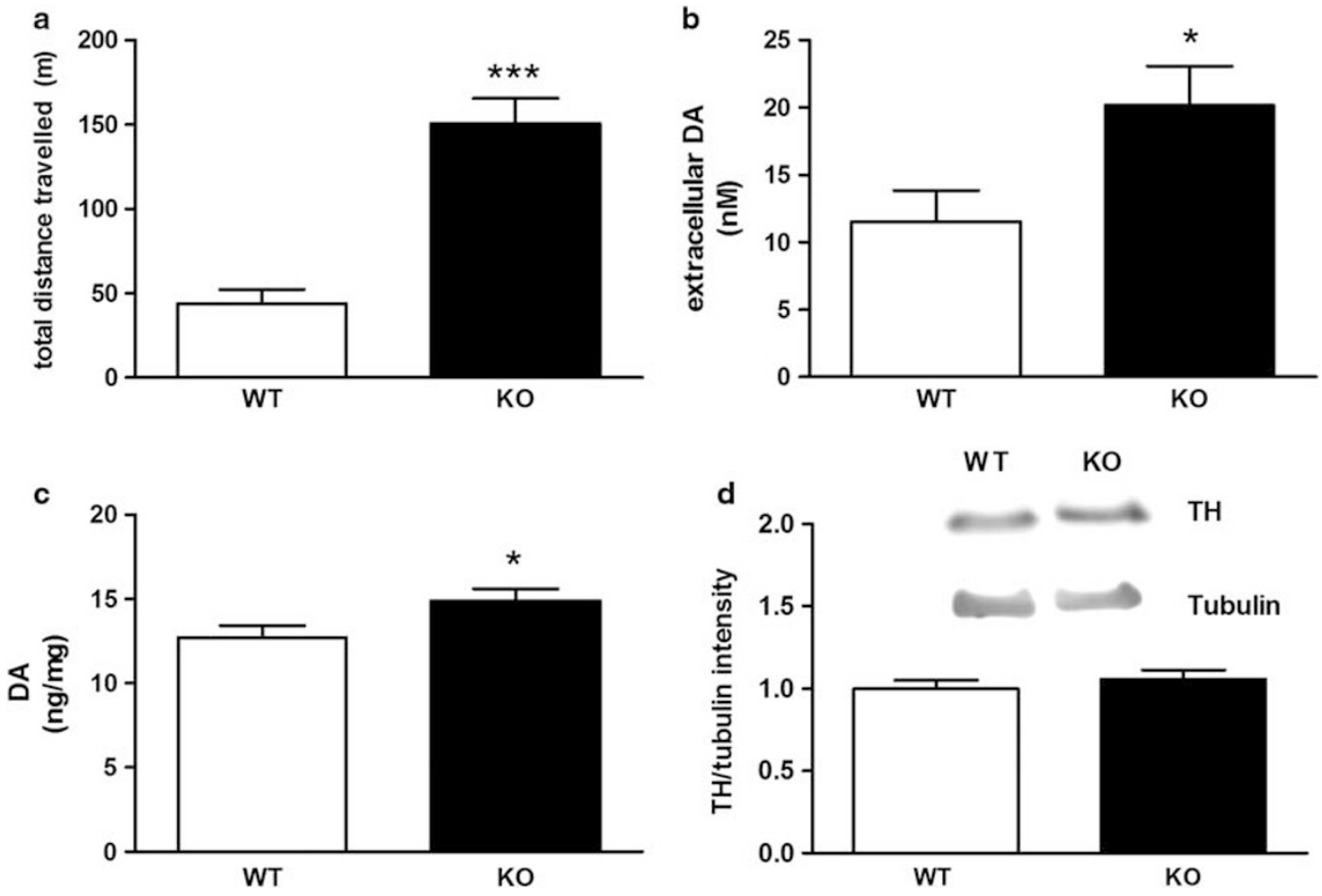

Figure 2 (a) Locomotor activity of wild type (WT) and knockout (KO) mice; horizontal distances were measured for 60 min in an open field: WT: $44.0 \pm 8.3 \mathrm{~m}, n=13 ; \alpha \mathrm{CaMKII-KO}$ : I $50.6 \pm$ I $5.1 \mathrm{~m}, n=12$ (unpaired two-tailed Student's t-test; **** $p<0.000$ I). (b) Extracellular dopamine levels in WT and $\alpha \mathrm{CaMKII-KO}$ mice: Dopamine concentrations in the right dorsal striatum were collected by quantitative low-perfusion microdialysis and analyzed by HPLC EC. WT: I I.54 \pm 2.3 I nM, n=7; $\alpha$ CaMKII-KO: $20.15 \pm 2.92$ nM, $n=10$, unpaired Student's $t$-test; * $p<0.05$ ). (c) Tissue levels of dopamine: freshly dissected dorsal striata were homogenized and extracted before measurement by HPLC ( $n=14$ per genotype; unpaired Student's t-test; * $p<0.05)$. (d) Densitometric analysis of western blots show no change in striatal TH expression between WT and KO animals; TH bands were normalized to tubulin; $n=7$; Student's t-test, $p>0.05$

Figure 3 (a) $\left[{ }^{3} \mathrm{H}\right]$ dopamine uptake kinetics in striatal synaptosomes of wild type $(\mathrm{WT})$ and knockout $(\mathrm{KO})$ animals: striatal synaptosomes were incubated with $0.1 \mu \mathrm{M}\left[{ }^{3} \mathrm{H}\right]$ dopamine and increasing concentrations of unlabeled dopamine $(0-3 \mu \mathrm{M})$ for $5 \mathrm{~min}$ at $37^{\circ} \mathrm{C}$. Non-specific uptake was determined in the presence of I $\mu$ M GBRI2909. $K_{d}$ and $B_{\max }$ values are not significantly different $\left(K_{m}\right.$ : WT: $88.3 \pm 30.7 \mathrm{nM}, \alpha C a M K I I-K O$ : III.2 $\pm 47.1 \mathrm{nM}$; $V_{\text {max }}$ : WT: $4.66 \pm 0.32 \mathrm{pmol} / \mathrm{mg}$ protein $/ \mathrm{min}, \alpha \mathrm{CaMKII}-\mathrm{KO}: 4.87 \pm 0.45 \mathrm{pmol} / \mathrm{mg}$ protein $/ \mathrm{min}$; WT $n=6, \mathrm{KO} n=5 ; p>0.05$ ). (b) Fast-scan cyclic voltammetry (FSCV) was used to measure dopamine release from striatal brain slices. Representative traces in control and $\mathrm{KO}$ animal exemplify the higher peak height in mutants compared with control. (c) Average of stimulated dopamine release in dorsal striatum of control and $\mathrm{KO}$ animals show an increased evoked dopamine release in $\mathrm{KO}$ animals ( $n=6$; $* p<0.05$, unpaired Student's t-test). (d) Densitometric analysis of VMAT2 protein levels in the striatum of WT and KO mice: bands were normalized to tubulin; $n=9-10$; Student's $t$-test, $p>0.05$ (e) Uptake of $\left.{ }^{3} \mathrm{H}\right]$ dopamine in striatal synaptic vesicles: vesicles were incubated with $\left.40 \mathrm{nM}{ }^{3} \mathrm{H}\right]$ dopamine for $10 \mathrm{~min}$ at $30^{\circ} \mathrm{C}$. Non-specific uptake was determined in the presence of $10 \mu \mathrm{M}$ reserpine; $n=3 ; p>0.05$ (f) Dopamine $D_{\text {, }}$ receptor levels as assessed by $\left[{ }^{3} \mathrm{H}\right] \mathrm{SCH} 23390$ binding: WT $B_{\max }=326.6 \pm 33.2 \mathrm{fmol} / \mathrm{mg}$ protein, $\mathrm{KO} B_{\max }=287.1 \pm 32.9 \mathrm{fmol} / \mathrm{mg} \mathrm{protein}, K_{\mathrm{d}}$ : WT $\left.K_{d}=1.55 \pm 0.76 \mathrm{nM}, \quad K O K_{d}=1.50 \pm 0.8 \mathrm{InM} ; \mathrm{WT} n=4, K O n=5\right)$. (g) Dopamine $D_{2}$ receptor levels as assessed by $\left[{ }^{3} H\right]$ raclopride: WT $B_{\max }=280.2 \pm 30.0 \mathrm{fmol} / \mathrm{mg}$ protein, $n=6 ; \mathrm{KO} B_{\max }=229.0 \pm 19.7 \mathrm{fmol} / \mathrm{mg}$ protein, $n=5 ; \mathrm{WT} K_{d}=7.18 \pm 2.15 \mathrm{nM}, \mathrm{KO} K_{d}=2.55 \pm 0.84 \mathrm{nM}$. $K_{d}$ and $B_{\max }$ values are not significantly different; Student's $t$-test, $p>0.05$. (h) Densitometric analysis of PSD-95 protein levels in the striatum of WT and KO mice: bands were normalized to tubulin; $n=7$; Student's $t$-test, $p>0.05$. 
radioligand-binding results, we also found that there were no significant changes in pDARPP32, pAkt, pERK1, or pERK2 levels as measured by immunoblotting (pDARPP32/
DARPP32 ratio: $\alpha$ CaMKII-KO: $1.23 \pm 0.24$, WT: $1.50 \pm 0.26$; $n=3 ; p=0.4856$; pAkt/Akt ratio: $\alpha$ CaMKII-KO: $1.43 \pm 0.11$, WT: $1.20 \pm 0.12 ; n=6-7 ; p=0.1875$; pERK1/ERK1 ratio:
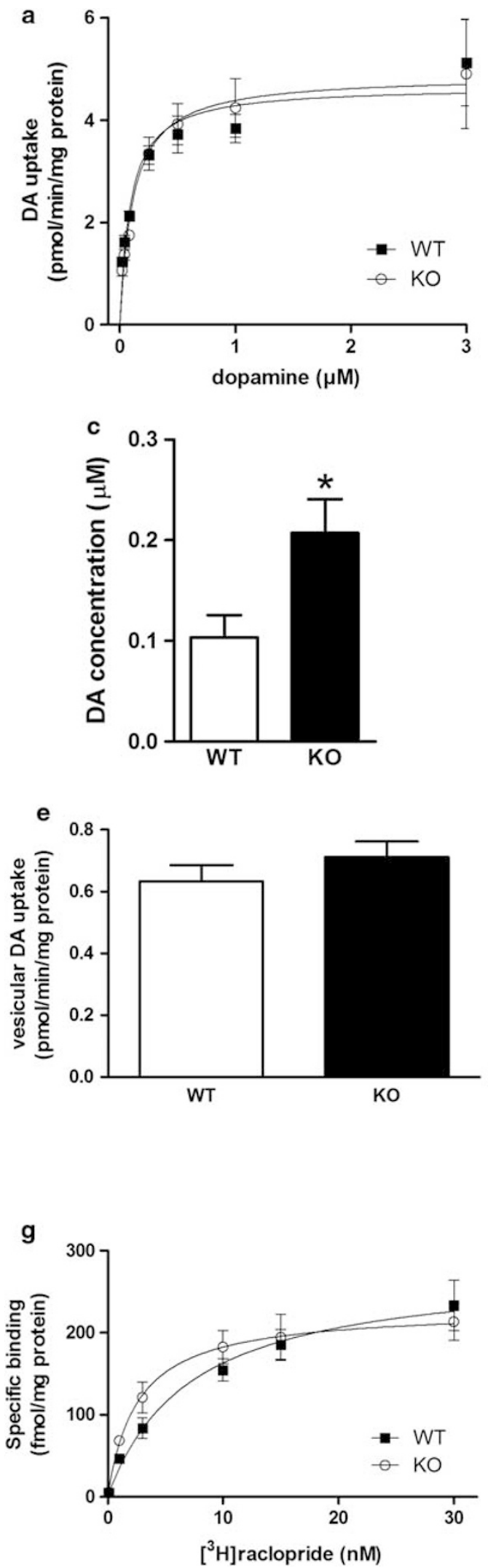

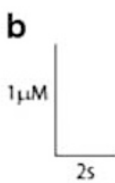

d WT KO
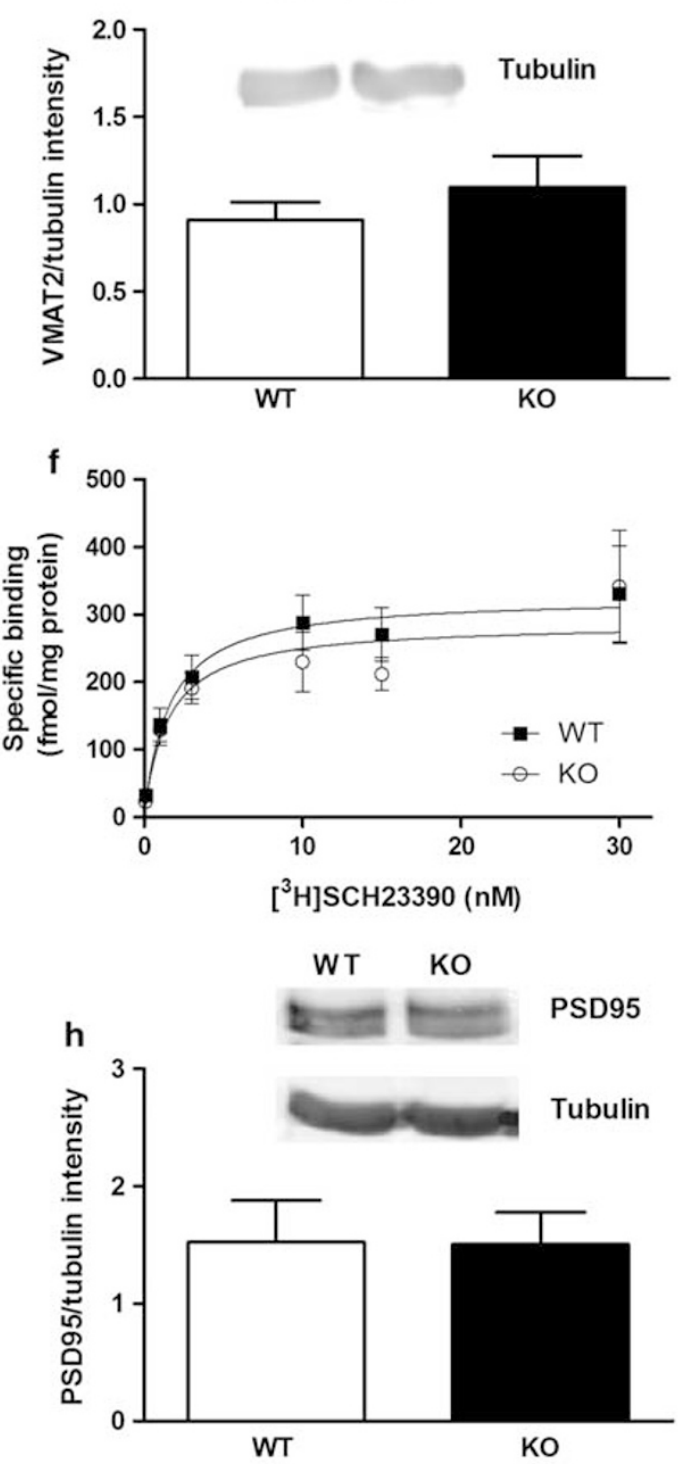
$\alpha$ CaMKII-KO: $0.73 \pm 0.07$, WT: $0.88 \pm 0.04 ; n=6 ; p=0.1015$; pERK2/ERK2 ratio: $\alpha$ CaMKII-KO: $0.70 \pm 0.14, \mathrm{WT}: 0.97 \pm$ $0.02 ; n=6 ; p=0.0877$; Student's $t$-test).

Persistent elevations of extracellular dopamine (ie, as a result of exposing mice to cocaine or of ablating DAT) can also result in downregulation of striatal levels of PSD95 (Yao et al, 2004). Accordingly, we examined whether PSD95 was downregulated in $\alpha \mathrm{CaMKII-KO}$ mice. However, quantitative immunoblotting for PSD95 from striatal extracts of WT and $\alpha$ CaMKII-KO mice did not reveal any differences between genotypes (Figure $3 \mathrm{~h}$ ).

\section{Amphetamine-Induced Dopamine Efflux in $\alpha$ CaMKII-KO Mice}

We previously reported that amphetamine-induced DATmediated substrate efflux was markedly attenuated in striatal synaptosomes and slices of $\alpha$ CaMKII-KO mice compared with wild-type littermate controls (Steinkellner et al, 2012). The decrease in substrate efflux is a functional consequence of ablated $\alpha$ CaMKII function rather than a result of a reduction of DAT surface expression (Steinkellner et al, 2012). We examined whether reverse transport by DAT was also blunted in vivo by implanting microdialysis probes into the dorsal striatum of these animals. This allowed to measure dopamine efflux after D-amphetamine administration ( $5 \mathrm{mg} / \mathrm{kg}$, i.p.) to freely moving animals. These experiments confirmed that, in agreement with our previous ex vivo measurements, dopamine efflux was substantially decreased in $\alpha$ CaMKIIKO mice (Figure 4a). The fact that efflux was not completely abolished might be a result of other kinases involved in the modulation of reverse transport or compensatory changes during development, as the $\alpha$ CaMKII-KO mice used in the
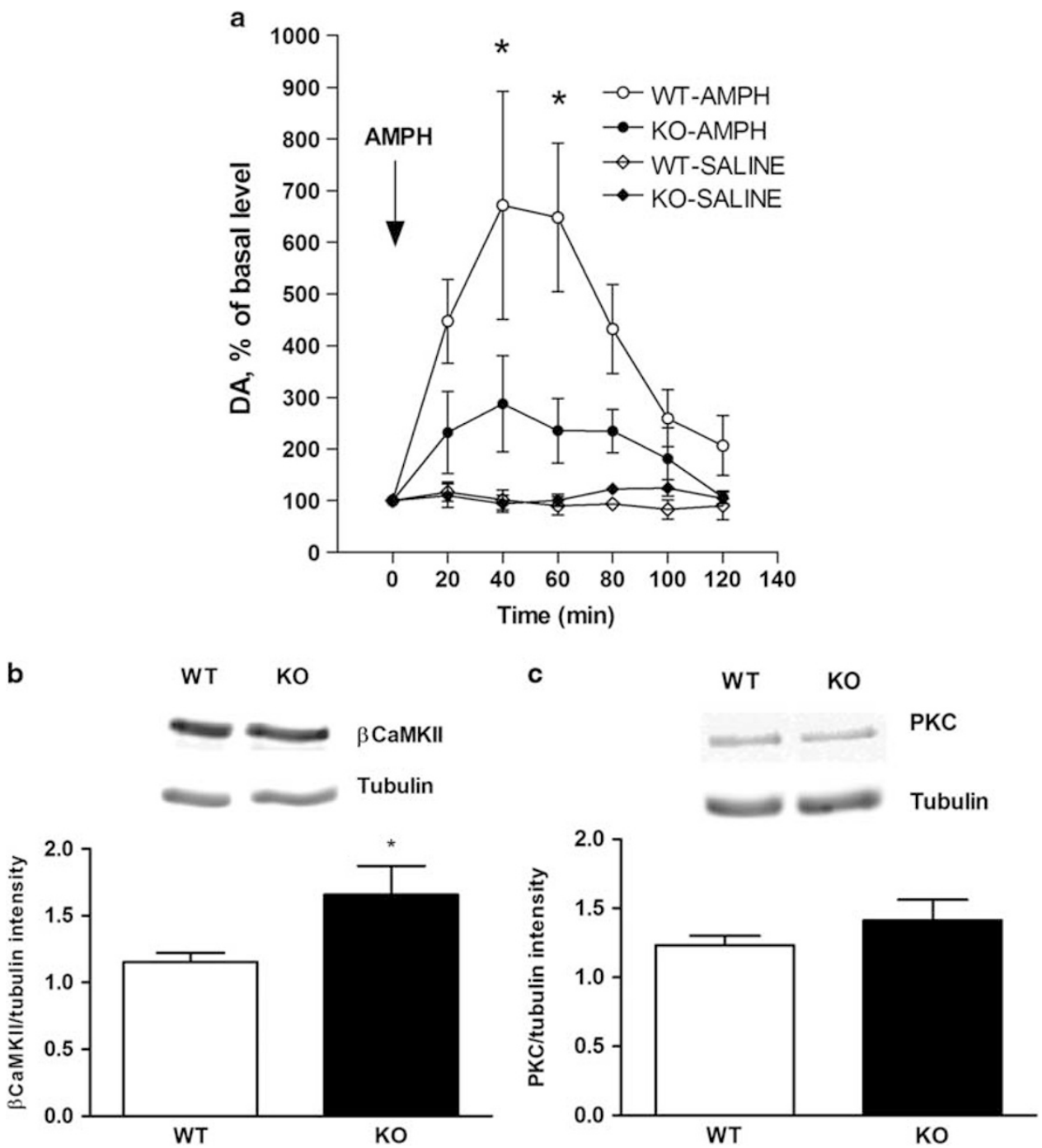

Figure 4 (a) D-amphetamine-induced dopamine release in the dorsal striatum of wild type (WT) and knockout (KO) animals in vivo: Microdialysis probes were inserted into the right dorsal striatum of WT and KO mice. Mice were allowed to recover for $24 \mathrm{~h}$ from the surgery before measurement of baseline dopamine concentrations. The day after, mice were injected with D-amphetamine $(5 \mathrm{mg} / \mathrm{kg}$ i.p.) and dopamine dialysates were collected for $2 \mathrm{~h}$. Amphetamine-induced dopamine release was normalized to baseline dopamine levels (see Figure 2 legend) and is presented as percentage of basal level. (b) Densitometric analysis of $\beta$ CaMKII protein levels in the striatum of WT and KO mice: bands were normalized to tubulin; $n=7$; Student's $t$-test, * $p<0.05$. (c) Densitometric analysis of PKC protein levels in the striatum of WT and KO mice: bands were normalized to tubulin; $n=9$; Student's $t$-test, $p>0.05$ 
experiments are global knockout mice. Hence, we also assessed whether the second most common CaMKII isoform, $\beta$ CaMKII, was altered and might be able to compensate for the loss of $\alpha$ CaMKII. In fact, we previously reported that $\beta$ CaMKII is part of the interactome of DAT (Steinkellner et $a l, 2012$ ) and have now found that $\beta$ CaMKII was upregulated in the striatum (Figure $4 \mathrm{~b}$ ). However, the presence of $\beta$ CaMKII does not suffice to rescue the reduction in amphetamine-triggered efflux, as the global CaMKIIinhibitor KN-93 had no appreciable effect on amphetaminetriggered efflux in $\alpha$ CaMKII-KO mice as described in Steinkellner et al (2012). Additionally, we measured whether there were any changes in PKC, which is another $\mathrm{Ca}^{2+}$ sensitive protein kinase and has also been shown to modulate DAT-reverse transport. However, we did not observe any changes in PKC protein levels in the striatum of wild type and $\alpha$ CaMKII-KO mice (Figure $4 \mathrm{c}$ ).

\section{Amphetamine-Induced Locomotor Activity is Decreased in $\alpha$ CaMKII-KO Mice}

Taken together, the findings suggested a cause-and-effect relation between the increase in steady-state extracellular dopamine levels, which were seen in the striata of $\alpha$ CaMKII$\mathrm{KO}$ mice, and their increased locomotor activity. However, the amphetamine-induced rise in extracellular dopamine was blunted in these animals (Figure 4). It was therefore of interest to examine how $\alpha$ CaMKII-KO mice responded to an amphetamine challenge. We injected mice with D-amphetamine and measured the distances traveled within $60 \mathrm{~min}$ in the OF (Figure 5a). When administered at a dose of $2 \mathrm{mg} / \mathrm{kg}, \mathrm{D}$-amphetamine induced a comparable increase in locomotor activity in wild type and $\alpha \mathrm{CaMKII-KO}$ mice (left hand set of bars in Figure 5a). When the dose of D-amphetamine was increased to $5 \mathrm{mg} / \mathrm{kg}$, locomotion was substantially increased in wild-type mice. In contrast, there was no appreciable additional effect in the $\alpha$ CaMKII-KO mice (Figure 5a, right hand sets of bars). These observations are consistent with the conclusion that $\alpha \mathrm{CaMKII-dependent}$ modulation of DAT is required to support the full-fledged acute behavioral effects of amphetamine.

\section{Amphetamine Sensitization is Blunted in $\alpha$ CaMKII-KO Mice}

The amphetamine-induced locomotor response is subject to sensitization, ie, repeated administration of amphetamine (or other psychostimulants including cocaine) results in an increase in the response (Steketee and Kalivas, 2011). This sensitization represents a long-lasting adaptation to the psychostimulant action and is triggered by the sequential activation of transcriptional programs (Nestler, 2005). We examined whether the blunted action of amphetamine sufficed to support the emergence of behavioral sensitization in the absence of $\alpha$ CaMKII: mice were injected once daily with $2 \mathrm{mg} / \mathrm{kg} \mathrm{D}$-amphetamine for six consecutive days, followed by a withdrawal period of 14 days and a challenge injection of $2 \mathrm{mg} / \mathrm{kg} \mathrm{D}$-amphetamine on day 21 . This dose was chosen because wild type and $\alpha$ CaMKII-deficient mice did not differ in their acute response (Figure 5a). Behavioral sensitization readily developed in wild-type mice as is evident from the continuous increase in locomotor activity in the first 6 days of amphetamine treatment and the roughly fivefold increase in distance covered within $60 \mathrm{~min}$ upon rechallenge on day 21 (open bars in Figure 5b). In contrast, compared with the first day of treatment, $\alpha \mathrm{CaMKII}-\mathrm{KO}$ mice did not respond with any further increase in locomotor activity from day 4 on, when they had covered approximately twice the distance traveled on the first day of D-amphetamine treatment (closed bars in Figure 5b). In order to address a possible mechanistic basis for the impaired sensitization observed in the mutant mice, we investigated the transcription factor cAMP response elementbinding protein (CREB), which is known to be induced after chronic exposure to addictive drugs and serves as a $\alpha$ CaMKII substrate (Nestler, 2005). Untreated $\alpha$ CaMKII$\mathrm{KO}$ or wild-type mice did not differ in their basal amounts of phospho-CREB (pCREB) levels in the striatum (Figure 5c). However, we found that amphetamine sensitization did not induce an increase in pCREB levels in $\alpha$ CaMKII-KO, whereas it induced a significant increase in the WT (Figure 5d).

\section{DISCUSSION}

The current experiments demonstrate that the full-fledged effect of amphetamine in vivo is contingent on the presence of $\alpha$ CaMKII. This was predicted from our earlier experiments that had been conducted in vitro (Steinkellner et al, 2012). However, dopaminergic neurons project to three major brain areas (ie, the nucleus accumbens in the ventral striatum, the dorsal striatum, and the prefrontal cortex) that contribute to a different extent to the acute biological response, to the emergence of addiction and to psychotic symptoms resulting from long-term abuse. They also differ in the level of DAT expression. Accordingly, the present experiments were designed to explore which effect of amphetamine was most dependent on the presence of $\alpha$ CaMKII. Clearly, the absence of $\alpha$ CaMKII did not uniformly impair the responses elicited by amphetamine in vivo. It was, for instance, surprising to see that the rewarding properties of amphetamine requiring effective memoryrelated processes were not affected to any appreciable extent. Similarly, we found that cocaine still induced robust place preference in $\alpha$ CaMKII-KO animals. In contrast, the absence of $\alpha$ CaMKII resulted in a substantial suppression of behavioral sensitization to amphetamine. While some of these differences can be rationalized in hindsight, it is evident that this was not to be predicted a priori.

On a global level, $\alpha$ CaMKII has been implicated in synaptic plasticity (Colbran and Brown, 2004). This is, in part, accounted for by its role in shaping glutamatergic synapses in the brain (Baucum et al, 2013). Moreover, the establishment of addictive behavior has been hypothesized to depend in part on the activity of $\alpha$ CaMKII in both, animal models and people ( $\mathrm{Li}$ et al, 2008). This conjecture is based on observations with several drugs of abuse such as cocaine (Pierce et al, 1998; Licata et al, 2004; Anderson et al, 2008), alcohol (Easton et al, 2013), or opioids (Lou et al, 1999). We used conditioned place preference (CPP) as a test to measure the addictive and rewarding potential of amphetamine and cocaine. Our findings show that the rewarding properties of amphetamine and cocaine were still preserved in $\alpha$ CaMKII-KO mice. This is in contrast to previous 

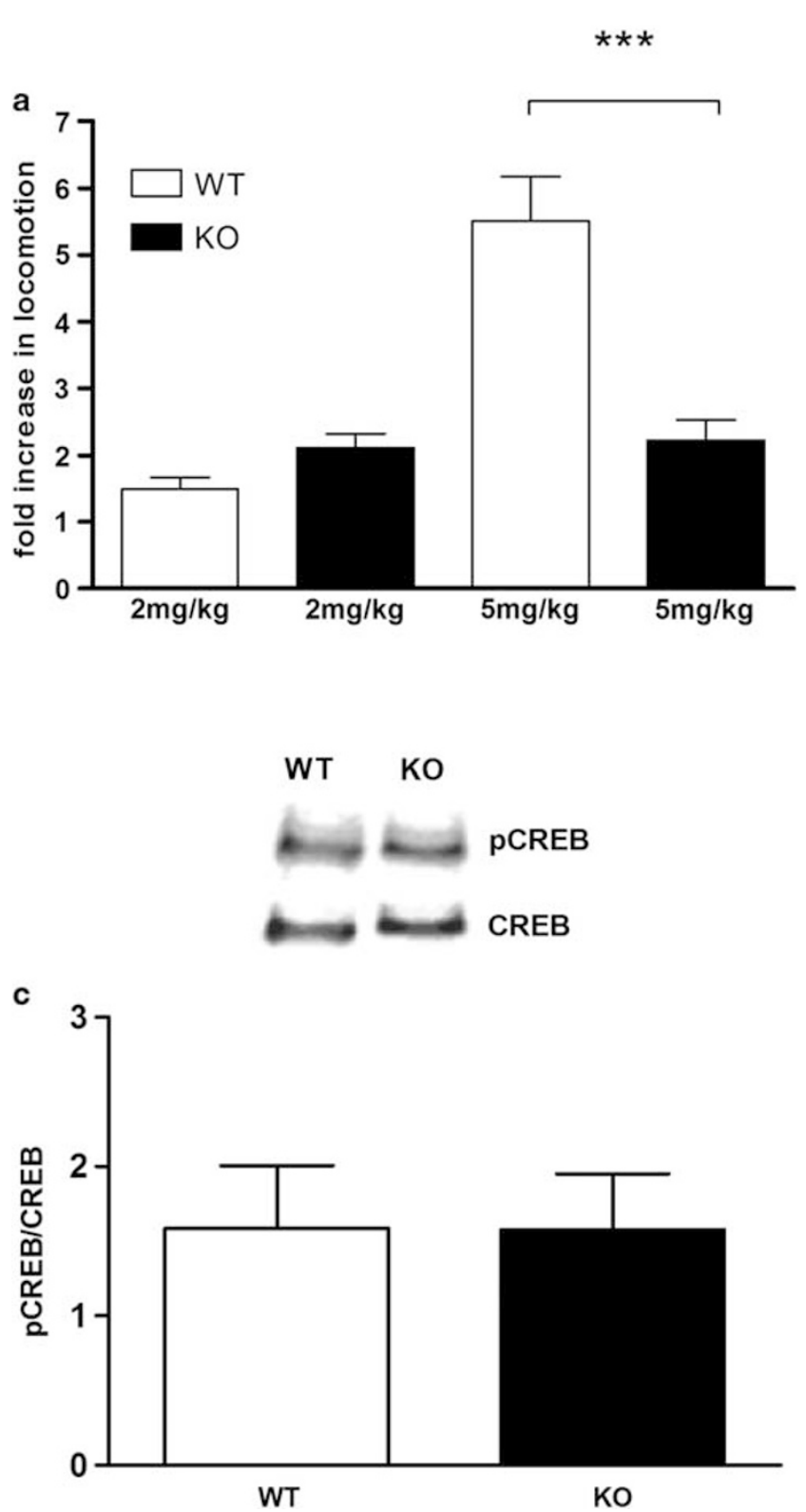

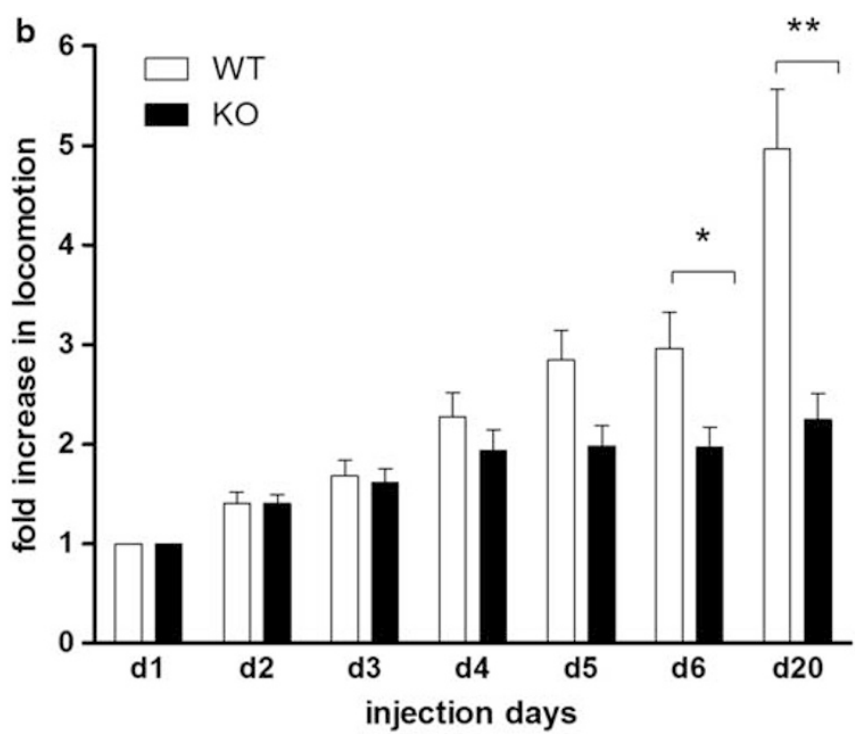

WT

SAL AMPH

SAL AMPH

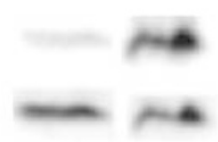

PCREB

CREB

d

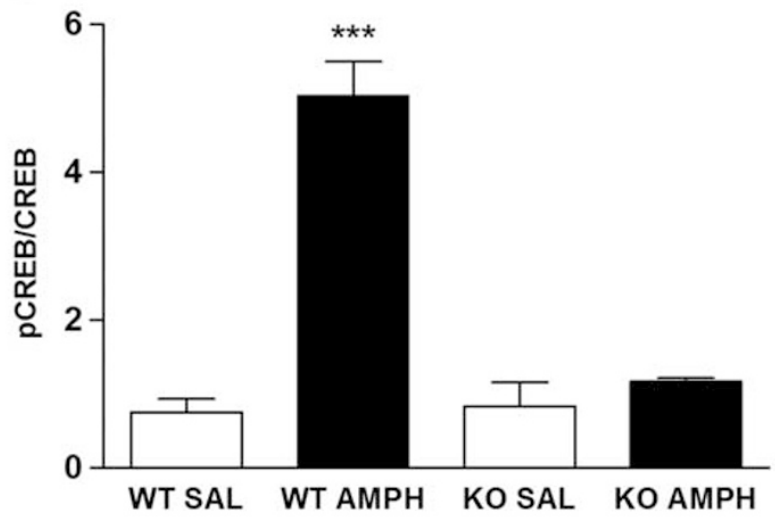

Figure 5 (a) Acute locomotor responses to D-amphetamine: mice were habituated to the open field for 60 min one day before they received an injection of D-amphetamine and subsequent recording of distances for another $60 \mathrm{~min}$. Total distances traveled after D-amphetamine were normalized to baseline locomotion and are expressed as fold increase in locomotion. One-way analysis of variance (ANOVA) followed by Tukey's multiple comparison test was used for statistical analysis; **** $<0.000$ I. (b) D-amphetamine sensitization: mice were habituated to open field chambers on day 0. On days I-6, mice were injected with $2 \mathrm{mg} / \mathrm{kg}$ D-amphetamine once daily and distances traveled were recorded immediately after injection for 60 min. Mice were withdrawn from D-amphetamine for 14 days before they received an additional drug injection on day 20. The distances traveled are normalized to the first day $(\mathrm{dl})$ of drug treatment; repeated measures two-way ANOVA revealed significant effects of genotype and treatment; $* p<0.05$, $* * * *<0.000 \mathrm{I}$. (c) Densitometric analysis of pCREB levels in the striatum of untreated wild type (WT) and knockout (KO) mice: bands were normalized to total CREB; $n=6-8$; Student's t-test, $p>0.05$. (d) Densitometric analysis of pCREB protein levels in the striatum of amphetamine-sensitized or saline-pretreated WT and KO mice: bands were normalized to total CREB; $n=3-4$; one-way ANOVA followed by Tukey's multiple comparison test was used for statistical analysis; ***** $p<0.0001$

findings in rats, where intra-hippocampal injection of the CaMKII-blocker KN-93-attenuated amphetamine-induced CPP (Tan, 2002). However, it should be pointed out that $\mathrm{CPP}$ does not represent the most reliable measurement of rewarding and addictive properties of a drug. Furthermore, this discrepancy may reflect species differences or indicate that KN-93 inhibits ion channels and kinases other than $\alpha$ CaMKII. Irrespective of this unresolved issue, our observations support the conclusion that the interaction of $\alpha$ CaMKII and DAT does not play any major role in the rewarding properties of amphetamine (and cocaine). It should be noted that amphetamine (and cocaine) still demonstrate significant CPP in mice lacking the DAT (Budygin et al, 2004) and even cocaine self-administration 
(Rocha et al, 1998). However, a different strain of DAT-KO mice clearly failed to acquire cocaine self-administration (Thomsen et al, 2009). Additionally, in mice with a cocaineinsensitive DAT, cocaine reward is lost (Chen et al, 2006). These observations indicate that DAT-related processes still seem to be most essential for the rewarding properties of these drugs. Potential compensatory and developmental changes in knockout mice have to be considered and certainly preclude definite conclusions. Besides, it has to be emphasized that CPP measures reward differently compared with self-administration: while CPP primarily measures the reinforcing effects of drugs, self-administration allows to discriminate between the reinforcing effects of a substance and the motivation to consume it. Hence, we cannot rule out that $\alpha$ CaMKII-KO mice would respond differently to amphetamine or cocaine self-administration. Regardless, small increases in psychostimulant-induced dopamine release might suffice to reach the threshold level required for the induction of reward-related behavior as measured by CPP. In fact, $\alpha$ CaMKII-KO mice still display dopamine efflux in response to amphetamine albeit significantly reduced compared with wild-type mice: we measured amphetamine-induced DAT-mediated dopamine efflux in the dorsal striatum by microdialysis and found that the amphetamine-induced dopamine efflux was significantly decreased in $\alpha$ CaMKII-KO animals. This is in accordance with our previous in vitro and ex vivo findings (Fog et al, 2006; Steinkellner et al, 2012).

Surprisingly, microdialysis also revealed that the extracellular dopamine concentrations are approximately twofold increased in the striatum of $\alpha$ CaMKII-KO mice and that these increased dopamine levels are the result of an elevated vesicular dopamine release without concomitant alterations in striatal VMAT2 protein levels or reserpine-sensitive VMAT2-mediated dopamine uptake into vesicles. The increase in vesicular dopamine release appears counterintuitive given that $\alpha$ CaMKII is the synapsin I-kinase, which defines the relative size of the reserve pool of neurotransmitters (Greengard et al, 1993). However, $\alpha$ CaMKII has also been shown to act as a bidirectional modulator in neurotransmitter release: it can both increase or decrease vesicular release (Chapman et al, 1995). In addition, the genetic ablation of $\alpha$ CaMKII in CA3 hippocampal neurons enhances stimulus-dependent vesicular glutamate release at the synaptic contact of their Schaffer collaterals with CA1 pyramidal neurons (Hinds et al, 2003). Thus, it was proposed thatapart from its role in mobilizing synaptic vesicles tethered to the cytoskeleton- $\alpha$ CaMKII can also have a nonenzymatic role and regulate the size of the readily releasable pool of vesicles at the active zone (Hojjati et al, 2007). In this model, $\alpha$ CaMKII limits this readily releasable pool; therefore its absence causes an increase in the number of vesicles at the active zone of $\alpha$ CaMKII-KO mice (Hojjati et al, 2007). The increased vesicular dopamine release that we observed in $\alpha$ CaMKII-KO mice is hence consistent with this expanded model of the role of $\alpha$ CaMKII in the presynaptic specialization. Besides, it is also in line with the finding that mesolimbic dopamine release is increased in a mouse model of Angelman syndrome, where $\alpha$ CaMKII is hyperphosphorylated and thereby rendered inactive (Riday et al, 2012).

The increased synaptic dopamine levels of $\alpha \mathrm{CaMKII-KO}$ mice were accompanied by a profound hyperactivity.
A similar result was obtained in C. elegans, where a null mutation of unc- 43 , a homolog of $\alpha$ CaMKII, caused hypermotility in the nematode (Reiner et al, 1999).

If $\alpha$ CaMKII-modulation of DAT were also important for the behavioral response to amphetamine, $\alpha$ CaMKII-KO animals ought to display a significantly reduced locomotor stimulation to an acute D-amphetamine injection. This prediction was verified: D-amphetamine $(5 \mathrm{mg} / \mathrm{kg})$ stimulated locomotion of wild-type mice by almost sixfold. In contrast, locomotion of $\alpha$ CaMKII-KO animals only doubled in response to amphetamine, consistent with the finding that amphetamine was still able to induce DAT-mediated dopamine efflux albeit to a much lesser extent than in wildtype mice. The difference in the locomotor response of $\alpha \mathrm{CaMKII}-\mathrm{KO}$ and wild-type mice provides incontrovertible evidence that $\alpha$ CaMKII is a modulator of DAT-reverse transport: $\alpha$ CaMKII favors a conformation of the transporter that is willing to efflux (Robertson et al, 2009). This conclusion is also supported by recently published analogous observations made in Drosophila melanogaster (Pizzo et al, 2014).

Repeated administration of amphetamine results in behavioral sensitization of locomotor responses in rodents (Steketee and Kalivas, 2011). Sensitization is also important for the emergence of addiction to psychostimulants; the underlying reprogramming of synaptic connections is orchestrated by the sequential activation of transcription factors, which creates a long-lasting memory of repeated drug exposure (Nestler, 2005). Our observations show that, in the absence of $\alpha$ CaMKII, sensitization to amphetamine is substantially impaired. This may arise from the reduced ability of amphetamine to cause dopamine release in mice lacking $\alpha$ CaMKII and to thus trigger a sustained neuronal activation, which eventually results in long-lasting synaptic facilitation. Presumably, the lack of $\alpha$ CaMKII limits the increase in dopamine release with repeated exposure, after a point, and therefore accounts for the reduced sensitization.

Additionally, the absence of $\alpha$ CaMKII may impair the emergence of a sensitized state, because $\alpha$ CaMKII is required for the full-fledged activation of the transcriptional program required for memory formation. The latter is supported by the finding that $\alpha \mathrm{CaMKII}-\mathrm{KO}$ mice displayed no increase in PCREB levels after amphetamine sensitization, whereas wild-type mice showed a significant increase in pCREB levels. At the present stage, it is impossible to differentiate between these two possibilities, but most likely a combination of both, a decreased dopamine efflux in response to amphetamine and an impaired $\alpha$ CaMKII-mediated signaling, contribute to the effects observed during amphetamine sensitization in $\alpha$ CaMKII-deficient mice.

Regardless of the underlying mechanism, these experiments further highlight the importance of $\alpha$ CaMKII in supporting the actions of amphetamine in vivo. Our experiments also underline that the relative contribution of $\alpha$ CaMKII to the behavioral actions of amphetamines might depend on the expression levels of DAT. They seem to be more pronounced in the striatum, where DAT expression levels are higher than in the nucleus accumbens, where DAT expression levels are low. Experiments looking more carefully into regional and molecular differences between the DAT/CaMKII interaction in those regions are currently being explored in our laboratories. 
In spite of this inherent limitation of our approach, it is attractive to speculate that subtle variations in the relative expression levels of DAT and of $\alpha$ CaMKII may contribute to inter-individual differences in the susceptibility to amphetamine addiction.

\section{FUNDING AND DISCLOSURE}

This research was supported by the Austrian Research Fund/FWF grants F3506, W1232 to HHS and F3510 to MF. HHS has received honoraria for lectures and consulting from Astra Zeneca, Lundbeck, Nycomed, Ratiopharm, Roche, Sanofi-Aventis, Serumwerk Bernburg, Torrex-Chiesi Pharma. MF has received honoraria for lectures and consulting from Amgen, Astra Zeneca, Astropharma, Baxter, Boehringer-Ingelheim, Celgene, Lundbeck, MerckSharp \& Dohme, Novartis-Sandoz, Ratiopharm and the Association of Austrian Sickness Funds. The remaining authors declare no conflict of interest.

\section{ACKNOWLEDGEMENTS}

We are indebted to the invaluable help of Drs Ype Elgersma, Rotterdam MC, and Dr Howard H. Gu, The Ohio State University, to establish the described research program.

\section{Author Contributions}

MW and HHS designed the project, MW, TDS, OK, UG, MF, DDP, RRG, and HHS supervised the project, analyzed data, TS, MF, and HHS wrote the first draft of the manuscript. TS, $\mathrm{BE}, \mathrm{AC}, \mathrm{LK}, \mathrm{MR}, \mathrm{GS}$, and EK designed and conducted all biochemical and behavioral pharmacology assays; LM, DL, EVE, TDS, and RRG designed and performed microdialysis and FSCV experiments and analyzed post-mortem tissue concentrations of monoamines and their metabolites. All authors contributed significantly to the writing of the final version of the article.

\section{REFERENCES}

Anderson SM, Famous KR, Sadri-Vakili G, Kumaresan V, Schmidt HD, Bass CE et al (2008). CaMKII: a biochemical bridge linking accumbens dopamine and glutamate systems in cocaine seeking. Nat. Neurosci 11: 344-353.

Baucum AJ, Brown AM, Colbran RJ (2013). Differential association of postsynaptic signaling protein complexes in striatum and hippocampus. J Neurochem 124: 490-501.

Buchmayer F, Schicker K, Steinkellner T, Geier P, Stübiger G, Hamilton PJ et al (2013). Amphetamine actions at the serotonin transporter rely on the availability of phosphatidylinositol-4,5bisphosphate. Proc Natl Acad Sci USA 110: 11642-11647.

Budygin EA, Brodie MS, Sotnikova TD, Mateo Y, John CE, Cyr M et al (2004). Dissociation of rewarding and dopamine transporter-mediated properties of amphetamine. Proc Natl Acad Sci USA 101: 7781-7786.

Chapman PF, Frenguelli BG, Smith A, Chen CM, Silva AJ (1995). The alpha-Ca2 + /calmodulin kinase II: a bidirectional modulator of presynaptic plasticity. Neuron 14: 591-597.

Chen R, Tilley MR, Wei H, Zhou F, Zhou FM, Ching S et al (2006). Abolished cocaine reward in mice with a cocaine-insensitive dopamine transporter. Proc Natl Acad Sci USA 103: 9333-9338.
Colbran RJ, Brown AM (2004). Calcium/calmodulin-dependent protein kinase II and synaptic plasticity. Curr Opin Neurobiol 14: 318-327.

Easton AC, Lucchesi W, Lourdusamy A, Lenz B, Solati J, Golub Y et al (2013). aCaMKII autophosphorylation controls the establishment of alcohol drinking behavior. Neuropsychopharmacology 38: 2735.

Elgersma Y, Fedorov NB, Ikonen S, Choi ES, Elgersma M, Carvalho OM et al (2002). Inhibitory autophosphorylation of CaMKII controls PSD association, plasticity, and learning. Neuron 36: 493-505.

Fog JU, Khoshbouei H, Holy M, Owens W a, Vaegter CB, Sen N et al (2006). Calmodulin kinase II interacts with the dopamine transporter $\mathrm{C}$ terminus to regulate amphetamine-induced reverse transport. Neuron 51: 417-429.

Franklin KBJ, Paxinos G (2008). The Mouse Brain in Stereotactic Coordinates. 3rd edition Academic Press (Elsevier): New York.

Gainetdinov RR, Bohn LM, Sotnikova TD, Cyr M, Laakso A, Macrae AD et al (2003). Dopaminergic supersensitivity in $G$ protein-coupled receptor kinase 6-deficient mice. Neuron 38: 291-303.

Ghisi V, Ramsey AJ, Masri B, Gainetdinov RR, Caron MG, Salahpour A (2009). Reduced D2-mediated signaling activity and trans-synaptic upregulation of D1 and D2 dopamine receptors in mice overexpressing the dopamine transporter. Cell Signal 21: 87-94.

Giros B, Jaber M, Jones SR, Wightman RM, Caron MG (1996). Hyperlocomotion and indifference to cocaine and amphetamine in mice lacking the dopamine transporter. Nature 379: 606-612.

Gnegy ME, Khoshbouei H, Berg KA, Javitch JA, Clarke WP, Zhang M et al (2004). Intracellular $\mathrm{Ca}^{2+}$ regulates amphetamine-induced dopamine efflux and currents mediated by the human dopamine transporter. Mol Pharmacol 66: 137-143.

Greengard P, Valtorta F, Czernik AJ, Benfenati F (1993). Synaptic vesicle phosphoproteins and regulation of synaptic function. Science (New York, NY) 259: 780-785.

Hinds HL, Goussakov I, Nakazawa K, Tonegawa S, Bolshakov VY (2003). Essential function of $\alpha$-calcium/calmodulin-dependent protein kinase II in neurotransmitter release at a glutamatergic central synapse. Proc Natl Acad Sci USA 100: 4275-4280.

Hell JW, Jahn R (1994). Preparation of synaptic vesicles from mammalian brain. Cell Biol 1: 567-574.

Hojjati MR, Van Woerden GM, Tyler WJ, Giese KP, Silva AJ, Pozzo-Miller L et al (2007). Kinase activity is not required for alphaCaMKII-dependent presynaptic plasticity at CA3-CA1 synapses. Nat Neurosci 10: 1125-1127.

Jones SR, Gainetdinov RR, Wightman RM, Caron MG (1998). Mechanisms of amphetamine action revealed in mice lacking the dopamine transporter. J Neurosci 18: 1979-1986.

Khoshbouei H, Wang H, Lechleiter JD, Javitch JA, Galli A (2003). Amphetamine-induced dopamine efflux. A voltage-sensitive and intracellular $\mathrm{Na}+$-dependent mechanism. J Biol Chem 278: 12070-12077.

Kristensen AS, Andersen J, Jørgensen TN, Sørensen L, Eriksen J, Loland CJ et al (2011). SLC6 neurotransmitter transporters: structure, function, and regulation. Pharmacol Rev 63: 585-640.

Kuhr WG, Wightman RM (1986). Real-time measurement of dopamine release in rat brain. Brain Res 381: 168-171.

Li C-Y, Mao X, Wei L (2008). Genes and (common) pathways underlying drug addiction. PLoS Comput Biol 4: e2.

Licata SC, Schmidt HD, Pierce RC (2004). Suppressing calcium/ calmodulin-dependent protein kinase II activity in the ventral tegmental area enhances the acute behavioural response to cocaine but attenuates the initiation of cocaine-induced behavioural sensitization in rats. Eur J Neurosci 19: 405-414.

Lou L, Zhou T, Wang P, Pei G (1999). Modulation of Ca2 + I calmodulin-dependent protein kinase II activity by acute and chronic morphine administration in rat hippocampus: differ- 
ential regulation of alpha and beta isoforms. Mol Pharmacol 55: 557-563.

Nestler EJ (2005). Is there a common molecular pathway for addiction? Nat Neurosci 8: 1445-1449.

Pierce RC, Quick E a, Reeder DC, Morgan ZR, Kalivas PW (1998). Calcium-mediated second messengers modulate the expression of behavioral sensitization to cocaine. J Pharmacol Exp Ther 286: 1171-1176.

Pizzo AB, Karam CS, Zhang Y, Ma CL, McCabe BD, Javitch JA (2014). Amphetamine-induced behavior requires CaMKII-dependent dopamine transporter phosphorylation. Mol Psychiatry 19: $279-281$.

Pizzo AB, Karam CS, Zhang Y, Yano H, Freyberg RJ, Karam DS et al (2013). The membrane raft protein Flotillin-1 is essential in dopamine neurons for amphetamine-induced behavior in Drosophila. Mol Psychiatry 18: 824-833.

Ramsey AJ, Laakso A, Cyr M, Sotnikova TD, Salahpour A, Medvedev IO et al (2008). Genetic NMDA receptor deficiency disrupts acute and chronic effects of cocaine but not amphetamine. Neuropsychopharmacology 33: 2701-2714.

Reiner DJ, Newton EM, Tian H, Thomas JH (1999). Diverse behavioural defects caused by mutations in Caenorhabditis elegans unc-43 CaM kinase II. Nature 402: 199-203.

Rickhag M, Owens WA, Winkler M-T, Strandfelt KN, Rathje M, Sørensen G et al (2013). Membrane-permeable C-terminal dopamine transporter peptides attenuate amphetamine-evoked dopamine release. J Biol Chem 288: 27534-27544.

Riday TT, Dankoski EC, Krouse MC, Fish EW, Walsh PL, Han JE et al (2012). Pathway-specific dopaminergic deficits in a mouse model of Angelman syndrome. J Clin Invest 122: 4544-4554.

Robertson SD, Matthies HJG, Galli A (2009). A closer look at amphetamine-induced reverse transport and trafficking of the dopamine and norepinephrine transporters. Mol Neurobiol 39: 73-80.

Rocha BA, Fumagalli F, Gainetdinov RR, Jones SR, Ator R, Giros B et al (1998). Cocaine self-administration in dopamine-transporter knockout mice. Nat Neurosci 1: 132-137.

Schultz W (2002). Getting formal with dopamine and reward. Neuron 36: 241-263.

Sandtner W, Schmid D, Schicker K, Gerstbrein K, Koenig X, Mayer F et al (2013). A quantitative model of amphetamine action on the serotonin transporter. Br J Pharmacol 171: 1007-1018.

Silva AJ, Paylor R, Wehner JM, Tonegawa S (1992). Impaired spatial learning in alpha-calcium-calmodulin kinase II mutant mice. Science 257: 206-211.
Sitte HH, Freissmuth M (2010). The reverse operation of $\mathrm{Na}(+)$ / $\mathrm{Cl}(-)$-coupled neurotransmitter transporters-why amphetamines take two to tango. J Neurochem 112: 340-355.

Sitte HH, Huck S, Reither H, Boehm S, Singer EA, Pifl C (1998). Carrier-mediated release, transport rates, and charge transfer induced by amphetamine, tyramine, and dopamine in mammalian cells transfected with the human dopamine transporter. J Neurochem 71: 1289-1297.

Snyder SH (1974). Proceedings: drugs, neurotransmitters, and psychosis. Psychopharmacol Bull 10: 4-5.

Steinkellner T, Freissmuth M, Sitte HH, Montgomery T (2011). The ugly side of amphetamines: short- and long-term toxicity of 3,4methylenedioxymethamphetamine (MDMA, 'Ecstasy'), methamphetamine and D-amphetamine. Biol Chem 392: 103-115.

Steinkellner T, Yang J-W, Montgomery TR, Chen W-Q, Winkler $\mathrm{M}-\mathrm{T}$, Sucic S et al (2012). $\mathrm{Ca}(2+) /$ calmodulin-dependent protein kinase II $\alpha$ ( $\alpha$ CaMKII) controls the activity of the dopamine transporter: implications for Angelman syndrome. J Biol Chem 287: 29627-29635.

Steketee JD, Kalivas PW (2011). Drug wanting: behavioral sensitization and relapse to drug-seeking behavior. Pharmacol Rev 63: 348-365.

Sulzer D (2011). How addictive drugs disrupt presynaptic dopamine neurotransmission. Neuron 69: 628-649.

Tan S-E (2002). Impairing the amphetamine conditioning in rats through the inhibition of hippocampal calcium/calmodulindependent protein kinase II activity. Neuropharmacology 42: 540-547.

Thomsen M, Hall FS, Uhl GR, Caine SB (2009). Dramatically decreased cocaine self-administration in dopamine but not serotonin transporter knock-out mice. J Neurosci 29: 1087-1092.

Yao W-D, Gainetdinov RR, Arbuckle MI, Sotnikova TD, Cyr M, Beaulieu J-M et al (2004). Identification of PSD-95 as a regulator of dopamine-mediated synaptic and behavioral plasticity. Neuron 41: 625-638.

Yui K, Goto K, Ikemoto S, Ishiguro T, Angrist B, Duncan GE et al (1999). Neurobiological basis of relapse prediction in stimulantinduced psychosis and schizophrenia: the role of sensitization. Molr Psychiatry 4: 512-523.

(i) (\$) $€$ This work is licensed under a Creative Commons Attribution-NonCommercial-NoDerivs 3.0 Unported License. To view a copy of this license, visit http:// creativecommons.org/licenses/by-nc-nd/3.0/ 